\section{(2) OPEN ACCESS}

\title{
Association between retirement and mortality: working longer, living longer? A systematic review and meta-analysis
}

\author{
Ranu Sewdas $\mathbb{B}^{1}{ }^{1}$ Astrid de Wind ${ }^{1,2,3}$ Sari Stenholm, ${ }^{4,5}$ Pieter Coenen, ${ }^{1}$ \\ Ilse Louwerse, ${ }^{1}$ Cécile Boot, ${ }^{1}$ Allard van der Beek ${ }^{1}$
}

\begin{abstract}
- Additional material is published online only. To view please visit the journal online (http://dx.doi.org/10.1136/ jech-2019-213023).

${ }^{1}$ Department of Public and Occupational Health,

Amsterdam Public Health Research Institute, Amsterdam UMC - Locatie VUMC, Amsterdam, Noord-Holland, The Netherlands ${ }^{2}$ Coronel Institute of Occupational Health, Amsterdam Public Health research institute, Amsterdam UMC - Locatie AMC, Amsterdam, North Holland, The Netherlands

${ }^{3}$ Behavioural Science Institute, Radboud Universiteit, Nijmegen, Gelderland, The Netherlands

${ }^{4}$ Department of Public Health, University of Turku, Turku, Finland

${ }^{5}$ Centre for Population Health Research, University of Turku, Turku, Finland
\end{abstract}

\section{Correspondence to} Dr Cécile Boot, Department of Public and Occupational Health, Amsterdam Public Health research institute, Amsterdam UMC, VU University Amsterdam, Amsterdam, The Netherlands; crl.boot@amsterdamumc.nl

Received 2 August 2019 Revised 3 January 2020 Accepted 26 January 2020

Check for updates

(C) Author(s) (or their employer(s)) 2020. Re-use permitted under CC BY-NC. No commercial re-use. See rights and permissions. Published by BMJ.

To cite: Sewdas $R$, de Wind A, Stenholm S, et al. J

Epidemiol Community Health 2020;74:473-480.

\section{ABSTRACT}

Aim This study summarised available evidence on the association between early and on-time retirement, compared with continued working, and mortality. Moreover, this study investigated whether and to what extent gender, adjustment for demographics and prior health status influence this association.

Methods A systematic literature search of longitudinal studies was conducted. A qualitative analysis of the included studies was performed, followed by a metaregression analysis to assess the influence of gender, prior health and demographics. Random-effects models were used in a meta-analysis to estimate the pooled effects for relevant subgroups identified in the meta-regression. Results In total, 25 studies were included. Adjustment for prior health and demographics influenced the association between retirement and mortality $(p<0.05)$. The results of the meta-analysis of 12 studies are presented for 'insufficiently adjusted' and 'fully adjusted' subgroups. There was no association between early retirement and mortality compared with working until retirement (fully adjusted subgroup: HR 1.05, 95\% Cl 0.87 to 1.28). On-time retirement was associated with a higher risk of mortality compared with working beyond retirement (insufficiently adjusted subgroup: HR 1.56, $95 \% \mathrm{Cl} 1.41$ to 1.73 ). However, in the subgroup that adjusted for prior health, on-time retirement was not associated with mortality (HR 1.12, 95\% Cl 0.98 to 1.28). Conclusion Early retirement was not associated with a higher risk of mortality. On-time retirement was associated with a higher risk of mortality, which might reflect the healthy worker effect. It is important to consider information on prior health and demographics when studying the association between retirement and mortality to avoid biased findings.special-featureunlocked

\section{BACKGROUND}

In many countries, the population is ageing due to increasing life expectancy and decreasing birth rates. ${ }^{1} 2$ To minimise the growing proportion of retirees compared with the active working population, many governments have raised the statutory retirement age and have linked retirement age to life expectancy. ${ }^{34}$ In most European countries, the statutory retirement age has gradually increased from 65 years in 2012 to 67 or 69 years in $2022 .^{5-7}$ Of particular concern, however, is whether and to what extent an increasing retirement age may affect the health of older people after retirement.

In recent years, there has been a growing interest in studying the impact of work and retirement on health. ${ }^{8-16}$ In general, working is beneficial for wellbeing and health. ${ }^{17-22}$ This is also illustrated by previous systematic reviews showing that a transition from work to retirement may lead to increasing general and physical health problems. ${ }^{8} 9$ However, retirement can also result in improvements in mental health. ${ }^{8} 9$ The conflicting results may be explained by the type and age of retirement, that is, whether early (eg, before 63 years in Finland, and before 65 or 60 years for men and women, respectively, in Austria) or on time (eg, between 63 and 67 years in Finland, and at 65 or 60 years for men and women, respectively, in Austria). For example, previous studies in Finland and the UK have shown that physical and mental health improve after early retirement, ${ }^{23} 24$ whereas a study in the USA found a decline in physical health after on-time retirement compared with working beyond retirement. ${ }^{25}$ These conflicting results are mostly from studies of subjective health outcomes and may represent rather acute effects of retirement. Therefore, it is more useful to examine the long-term association between retirement and health, and stratify the analysis by type of retirement (early and on-time retirement).

There are two prevailing beliefs when it comes to the association between retirement and mortality. The first belief is that people who retire (early) may live longer than those who continue working, since retirement may serve as a release from the adverse effects of work demands. ${ }^{26} 27$ The other belief is that those who retire (early) die sooner, since retirees no longer experience the beneficial health effects of work, and/or workers in poor health retire earlier than workers in good health. ${ }^{28} 29$ These different explanations are evident in a previous systematic review that found mixed evidence on the effects of on-time and early retirement as risk factors for mortality when analysed separately. ${ }^{30}$ More recently, several studies have assessed the impact of retirement age on mortality, but they have also had mixed findings. ${ }^{31-46}$ A summary of available evidence on this topic and an analysis of whether and to what extent prior health status influences the association between retirement and mortality would help to clarify the situation. In addition, possible gender differences in this context are important to consider since in some countries women have a lower retirement age, and women live longer than men in general worldwide. ${ }^{47}$

Therefore, the main objective of this study was to summarise available evidence from longitudinal 
studies on the association between early and on-time retirement, compared with continued work participation, and mortality. Moreover, this study investigated whether and to what extent gender, adjustment for demographics and prior health status influence the association between retirement and mortality.

\section{METHODS}

A systematic review, meta-regression analysis and meta-analysis were conducted to explore the association between retirement (early and on-time) and mortality. The protocol for the current study was registered in PROSPERO (International Prospective Register of Systematic Reviews) a priori. ${ }^{48}$ The current study was reported according to the Preferred Reporting Items for Systematic Reviews and Meta-Analyses guidelines. ${ }^{49}$

\section{Search strategy and selection criteria}

A literature search was conducted in March 2018 in the following databases: PubMed, Embase, Cumulative Index to Nursing and Allied Health Literature (CINAHL), PsycINFO, the International Bibliography of the Social Sciences (IBSS), ABI/ Inform, Business Source Elite and EconPapers. The search terms were retirement, pension, early pension, mortality, survival and longevity. We searched for longitudinal studies (both retrospective and prospective) that compared either early retirement and working until retirement, or on-time retirement and working beyond retirement. Studies that assessed the impact of work disability pension on mortality were excluded since health is inherent to this exit route. ${ }^{23} 24$ Studies were included if they used all-cause or cause-specific mortality as an outcome. Only studies written in English and published in peer-reviewed journals were selected.

\section{Study selection}

First, two reviewers independently screened $20 \%$ of the potentially relevant titles and abstracts for eligibility based on the inclusion and exclusion criteria. The remaining titles and abstracts were screened by one reviewer. Full-text articles were retrieved for further assessment of eligibility when (1) references appeared to be eligible based on title and abstract, (2) consensus could not be reached, or (3) there was no abstract available. Screening of full-text articles was performed by two reviewers. Discrepancies were discussed until consensus was reached. Finally, the reference lists of the included studies were checked for other potentially relevant studies.

\section{Data extraction}

One reviewer extracted data from all selected studies, and these data were checked by a second reviewer. The following information was extracted: first author, study design, data set used, country, description of pension system, study period, years of follow-up, sample size, characteristics of study population and confounders. Information on the effect estimate (adjusted for confounders) and variance or SE of the effect estimate (calculated from the CI or p value) was extracted for the meta-regression and subsequent meta-analysis. For studies with missing information, the corresponding author was contacted to request the required data.

\section{Quality assessment}

For methodological quality assessment, nine criteria based on Hayden et al's checklist ${ }^{50}$ were used (see table 1). Each item was scored as positive $(+)$ or negative $(-)$, whereby negative

\begin{tabular}{|c|c|}
\hline Study objective & Positive if a clearly stated objective is described. \\
\hline $\begin{array}{l}\text { Study population } \\
\text { definition }\end{array}$ & $\begin{array}{l}\text { Positive if the main features of the study population are clearly } \\
\text { described, including the inclusion and exclusion criteria. }\end{array}$ \\
\hline Study design & $\begin{array}{l}\text { Positive if the study measured retirement (exposure) before } \\
\text { mortality (outcome). }\end{array}$ \\
\hline Outcome & Positive if mortality was clearly defined. \\
\hline Exposure-a & $\begin{array}{l}\text { Positive if actual retirement is used as exposure instead of } \\
\text { (early) retirement offer/window/reform, since in the latter case } \\
\text { it is not known if the exposed group is actually retiring earlier } \\
\text { than the non-exposed group. }\end{array}$ \\
\hline Exposure-b & $\begin{array}{l}\text { Positive if retirement information is register-based instead of } \\
\text { self-reported. }\end{array}$ \\
\hline Study confounding & $\begin{array}{l}\text { Positive if age, gender (if applicable) and socioeconomic } \\
\text { position are taken into account as confounders. }\end{array}$ \\
\hline $\begin{array}{l}\text { Study confounding } \\
\text { health }\end{array}$ & $\begin{array}{l}\text { Positive if adjusted for health status (eg, self-rated health, } \\
\text { disability, pre-existing health conditions, hospitalisations) prior } \\
\text { retirement, or stratified for health status prior retirement, or } \\
\text { excluding participants who retired due to poor health. }\end{array}$ \\
\hline Data analysis & $\begin{array}{l}\text { Positive if appropriate statistical model is used to evaluate } \\
\text { data, and if point estimates and measures of precision (eg, } \mathrm{Cl} \text { or } \\
\text { SE) were described. }\end{array}$ \\
\hline
\end{tabular}

was seen as potential bias. One reviewer performed the quality assessment for all selected studies, and this assessment was checked by a second reviewer. A high-quality study was defined as a study with a positive score on at least $50 \%$ of the criteria in the checklist.

\section{Qualitative analysis}

Results from the studies are presented in online supplementary table 1, with '+' indicating higher risk of mortality, '-' indicating lower risk of mortality or ' 0 ' indicating no association.

\section{Summary measures}

Studies with an effect measure (ie, risk ratio, OR or HR) were included in the meta-regression and meta-analysis. From these studies, effect sizes were used to estimate (if not already presented) an HR (including 95\% CI) for mortality. For studies that investigated the influence of an older age at retirement on mortality (without specifying the type of retirement or the comparison group), the inverse of the effect estimate was calculated to determine the influence of 'retiring earlier' compared with retiring later on mortality.

In the meta-regression, we determined whether and to what extent adjustment for prior health status, demographics and gender influenced the association between retirement and mortality. Demographics included age, gender (if applicable) and socioeconomic position (ie, education and/or income). To investigate whether and to what extent on-time retirement differed from retiring earlier, we also included retirement type in the meta-regression. In the meta-regression analysis, the pooled HRs were stratified by adjustment for these study characteristics. We used linear regression models to identify the influence of these study characteristics on the estimated risk of mortality (expressed in beta; significance $\mathrm{p}<0.05$ ).

In the meta-analysis, the HRs were pooled using Review Manager V.5.3, and presented in forest plots by type of retirement (ie, early retirement, on-time retirement and retiring earlier), which was defined by the authors of the current study. Other subgroup analyses were presented in forest plots based on the results from the meta-regression analysis. Heterogeneity of the 


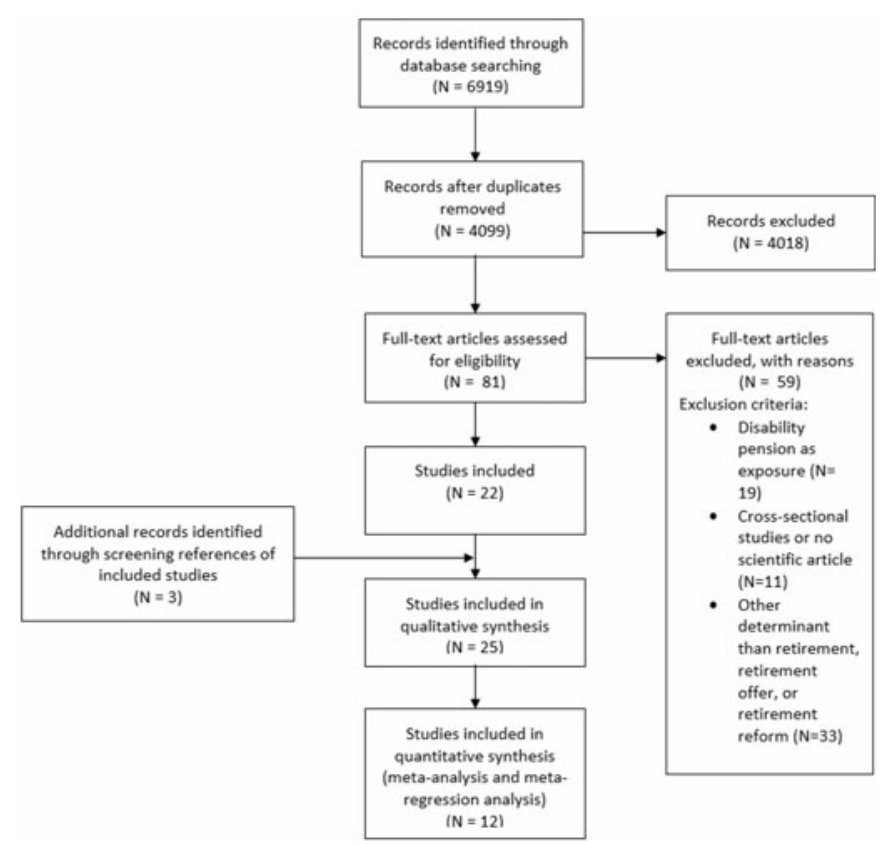

Figure 1 Flow diagram.

results was assessed using the $\mathrm{I}^{2}$ statistic. Since $\mathrm{I}^{2}$ was above $50 \%$ in most forest plots, random-effect models were applied for statistical pooling.

\section{RESULTS \\ Study selection}

Figure 1 presents a flow diagram of the search, screening and selection process. The search strategy resulted in a total of 6919 records. After removing duplicates, 4099 unique records were screened by title and abstract. A total of 81 full-text publications were selected for further investigation. Finally, 22 studies met the inclusion criteria and 3 more studies were identified by reference list screening. Thus, a total of 25 studies were included in the current study.

\section{Study characteristics}

Online supplementary table 1 presents an overview of the characteristics of the included studies. Most studies were cohort studies, and a few studies used an instrumental variable approach to study the association between retirement and mortality. The follow-up periods in the included studies ranged from 2 to 31 years. Most studies were conducted in European countries (eg, Sweden, Denmark, the Netherlands, UK, Austria, Greece, Germany and Norway) and the USA. A few studies were conducted in Canada, Israel or Japan. The majority of the studies had a pension system with a statutory retirement age of 65 years and the possibility to retire early. Seventeen studies investigated the association between early retirement and mortality, ${ }^{26-29} 31373840414546 \quad 51-56$ while three studies investigated the association between on-time retirement and mortality. $^{35} 5758$ One study investigated the association between early retirement and mortality, as well as the association between on-time retirement and mortality. ${ }^{34}$ Four studies investigated the influence of a change in the retirement age or the influence of having a mandatory retirement rule at work compared with no mandatory retirement rule. ${ }^{44}$ 59-61 A mandatory retirement rule implies that workers have to retire once they reach a certain age and are not allowed to prolong work participation.

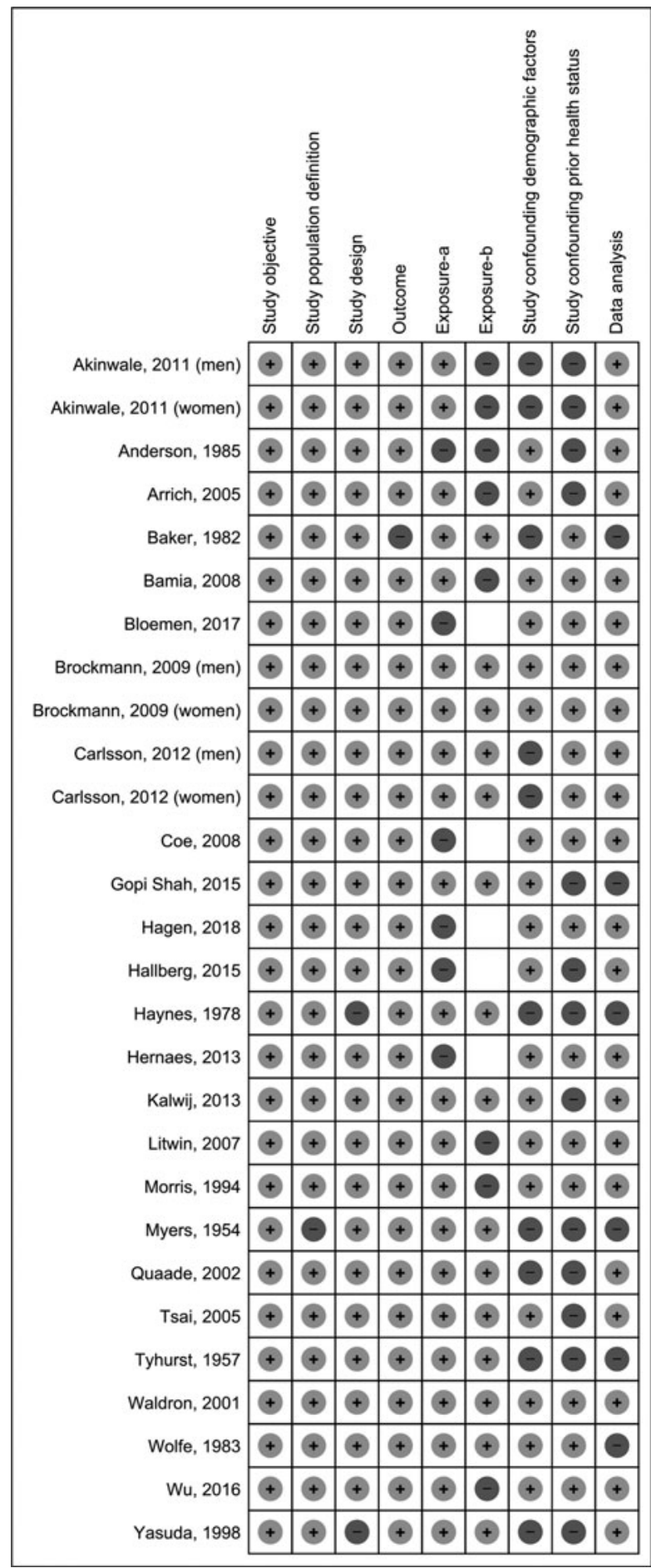

Figure 2 Risk of bias of included studies. The figure shows risk of bias (ie, + for low risk of bias, - for high risk of bias) for all criteria (ie, study objective, study population definition, study design, outcome, exposure, study confounding (demographics or prior health status) and data analysis).

\section{Risk of bias}

The outcome of the quality assessment is presented in figure 2 . Two studies had a low risk of bias on all items. All other studies $(n=23)$ had a high risk of bias; for example, some studies used a (early) retirement offer/window/reform as exposure, which is not the same as actual (early) retirement. Most studies had a high risk of bias for study confounding, that is, did not include prior health status or demographics as confounders in the analyses. However, 
Table 2 Univariate meta-regression models with retirement, gender, adjustment for prior health status and adjustment for demographics modelled as independent variables and effect size (expressed in beta) as dependent variable

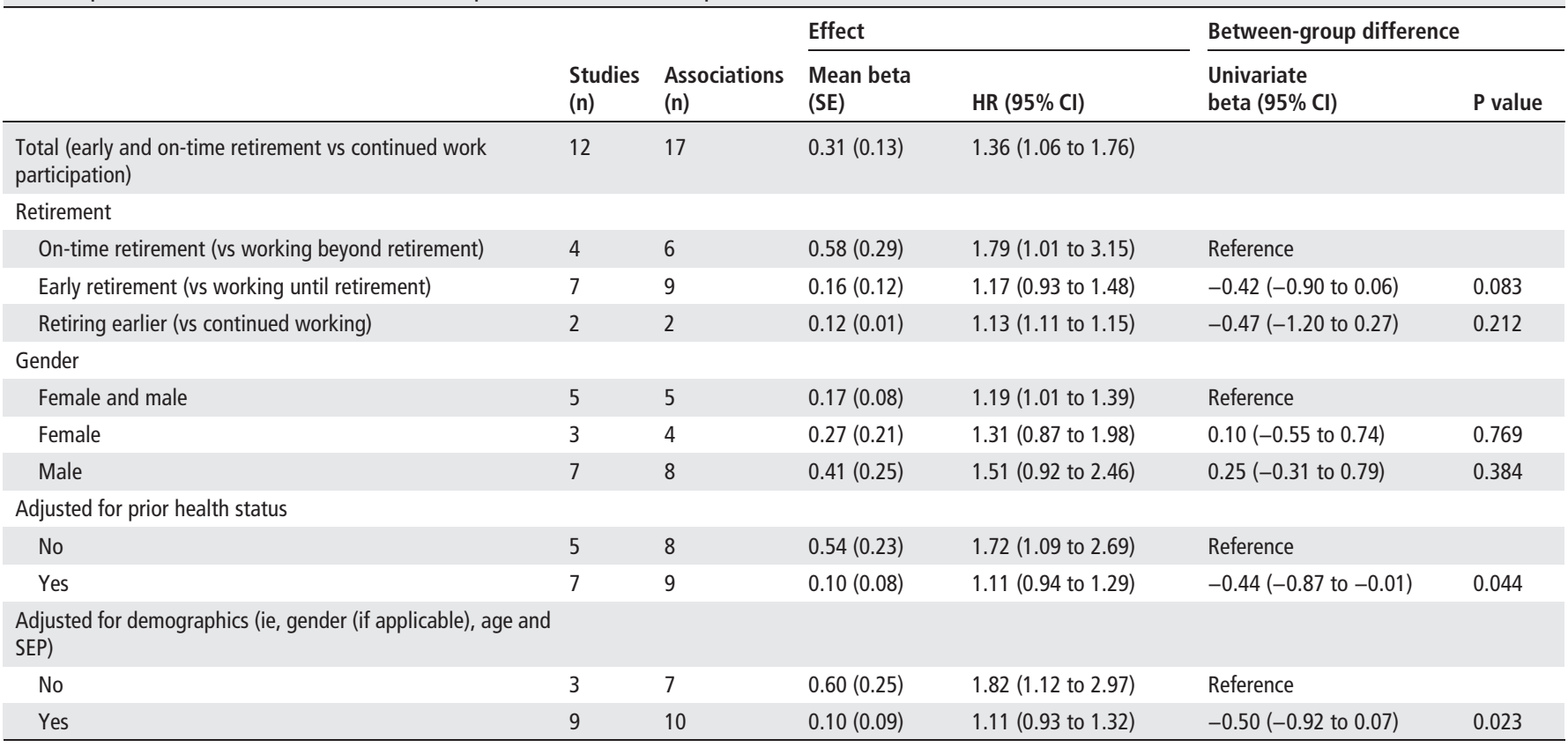

SEP, socioeconomic position

all studies had high methodological quality and were included in the meta-analysis (studies with an estimated effect measure).

\section{Early retirement versus working until retirement}

In the 18 studies that investigated the association between early retirement compared with continued work participation and mortality, a total of 20 associations were reported. Eight associations revealed a higher risk of mortality for early retirement, five associations pointed to a lower risk of mortality, and seven associations showed no association between early retirement and mortality (see online supplementary table 1 ).

In the meta-regression analysis, we found that the association between retirement and mortality was statistically weaker when adjusting for prior health status or demographics (table 2). No significant differences $(p<0.05)$ in effect sizes were found between retirement type and gender. Therefore, in the meta-analysis, forest plots were calculated for the subgroup of studies adjusted for prior health status and demographics (ie, 'fully adjusted subgroup') and studies not adjusted for prior health status and/or demographics (ie, 'insufficiently adjusted subgroup').

A total of seven studies with nine associations were used to estimate a pooled HR for early retirement and mortality (figure 3 ). The pooled HR for four associations in the insufficiently adjusted subgroup of studies showed no association between early retirement and mortality (HR 1.32 , 95\% CI 0.95 to 1.81 ). The pooled HR for five associations in the fully adjusted subgroup of studies was 1.05 (95\% CI 0.87 to 1.28 ).

\section{On-time retirement versus working beyond retirement}

Four studies, with a total of six associations, investigated the association between on-time retirement and mortality. Four associations revealed a higher risk of mortality for on-time retirement, and two studies showed no association.

All studies with six associations were used to estimate a pooled HR (see figure 4). Three studies with four associations were classified as an insufficiently adjusted subgroup. One study
(Arrich $e t a l^{57}$ ) was based only on patients with stroke. The insufficiently adjusted subgroup of studies showed that on-time retirement was associated with a higher risk of mortality compared with working beyond retirement (HR 1.56, 95\% CI 1.41 to 1.73 ). No study could be classified as fully adjusted group, but it was possible to classify two associations in a subgroup adjusted only for prior health status. The pooled HR for two associations adjusted for prior health status was 1.12 (95\% CI 0.98 to 1.28).

\section{Other comparisons}

Three studies investigated the influence of retiring earlier on mortality without specifying retirement type or comparison group (online supplementary table 1). Two studies revealed a higher risk of mortality for retiring earlier, whereas one study showed no association. A pooled HR was estimated based on two associations and showed that retiring earlier resulted in higher mortality rates for the fully adjusted subgroup of studies (HR $1.12,95 \%$ CI 1.09 to 1.16$)$.

\section{DISCUSSION}

In the current study, we showed that early retirement compared with working until retirement was not associated with mortality. We also showed that in the subgroup of studies that were insufficiently adjusted, on-time retirement was associated with a higher risk of mortality compared with working beyond retirement. However, in the subgroup of studies that adjusted for prior health, on-time retirement was not associated with mortality and the effect size was smaller than in the insufficiently adjusted subgroup of studies. Furthermore, we found that it is important to consider the influence of prior health status and demographics on the association between retirement and mortality to avoid biased findings.

One major finding was that there was no statistically significant association between early retirement (excluding work disability pension) and mortality. Similarly, in the qualitative analysis, the majority of studies (mostly in the field of 


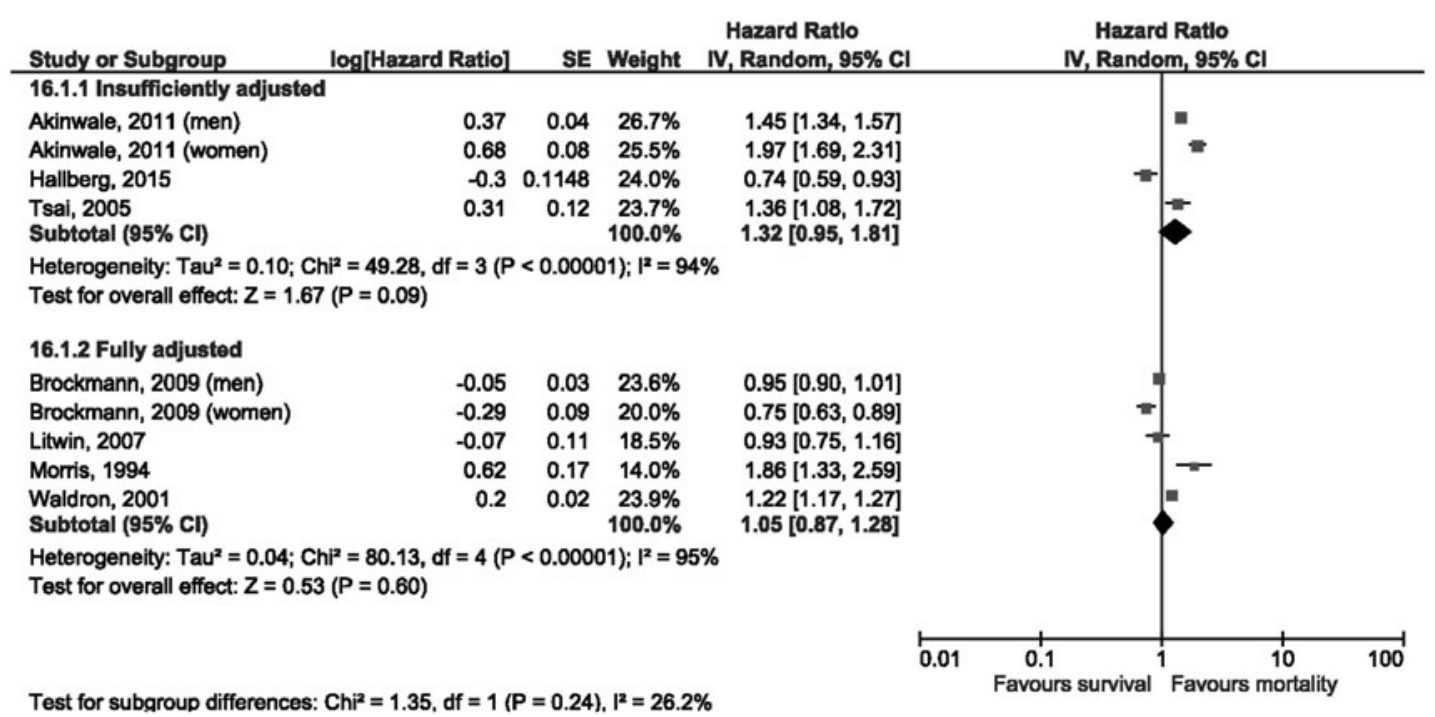

Figure 3 Effect sizes for studies investigating the association between early retirement compared with working until retirement and mortality. IV, inverse variance.

economics) had no association between early retirement and mortality. This can perhaps be explained by a previous study that showed both poor health and good health can influence the decision to retire early. ${ }^{62}$ Older healthy workers may voluntarily decide to retire early to enjoy their life or fulfil other goals. ${ }^{62} 63$ However, there could also be a group of workers who are 'forced' to retire early, for example, because they have been fired at a relatively older age. A previous study in the Netherlands found that workers who preferred a later retirement actually retired much earlier than expected perhaps due to lack of choice. ${ }^{64}$ Such involuntary retirement can have more negative consequences on health than voluntary retirement. ${ }^{8} 65$ A previous systematic review found that an early exit from work has more adverse health effects among lower socioeconomic groups compared with higher socioeconomic groups. ${ }^{66}$ For example, people working in manual occupations could experience a different impact of (early) retirement on health than highly educated white-collar workers. We recommend further research to consider differences between socioeconomic groups and the actual voluntary nature of retirement.
The findings of the current study demonstrate that without adjustment for prior health status, on-time retirement appears to be associated with mortality. In the subgroup of studies that adjusted for prior health, on-time retirement was not associated with mortality. This finding may reflect a healthy worker effect, whereby healthy persons are more likely to work beyond retirement, and unhealthy persons are more likely to exit from the workforce. ${ }^{67-71}$ Unlike our result, a previous systematic review by Shim et $a^{30}$ found mixed results on the association between ontime retirement and mortality, meaning that some included studies found no effect or a lower risk of mortality for those retiring on time. However, the authors included studies that used the general population as a reference group to examine this association, and it is well known that the general population has higher mortality rates compared with the working population, especially compared with those working beyond retirement. ${ }^{72}$ The difference in reference groups between the aforementioned systematic review and the current study could explain these conflicting results. This shows that it is important to carefully choose the reference group. The increased risk of mortality among those who retire

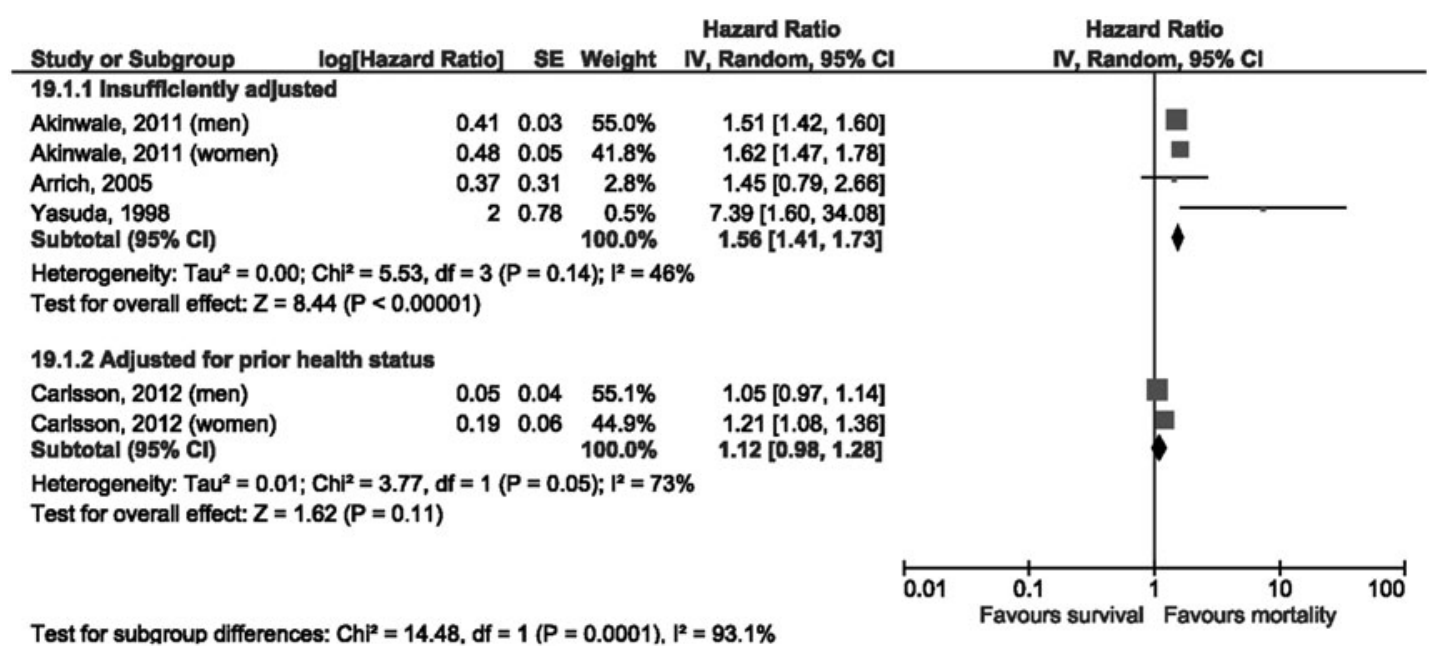

Figure 4 Effect sizes for studies investigating the association between on-time retirement compared with working beyond retirement and mortality. IV, inverse variance. 
on-time compared with those who work beyond retirement is most likely attributable to the healthy worker effect.

With regard to the role of gender, in the meta-regression analysis, we found no significant difference in effect size by gender. However, looking at some of the individual studies that did stratify by gender, different effect sizes for men and women were found. ${ }^{31}{ }^{34}{ }^{35}$ For example, Carlsson et $a l^{35}$ found that on-time retirement was associated with an increased risk of mortality for women, but not for men. The absence of a significant difference in the meta-regression analysis could be explained by the relatively small number of studies in the subgroup of studies among women $(n=3)$. Since some countries are applying different statutory retirement ages for men and women, further studies are needed to elucidate the gender differences in the association between retirement and mortality.

A strength of the current study is that we summarised available evidence from longitudinal studies on the association between retirement and mortality. To our knowledge, this is the first study that combines the results of the literature by conducting a meta-analysis. Another strength is that we compared the results between studies that did and did not adjust for prior health status and demographics. By doing so, we were able to contribute to an important discussion in the literature: whether the timing of retirement is related to the risk of mortality, independent of prior health status. Moreover, we were able to investigate whether the association between retirement and mortality varied across study characteristics related to the adjustment for demographics, gender and retirement type.

This study also had limitations. First, the assessment of the full-text articles by two reviewers to identify discrepancies avoided false positives, but it did not address false negatives. Therefore, it is possible that relevant studies were missed. However, we minimised this risk by screening the reference lists of the included studies to identify other relevant studies. Second, since risk estimates differed among the included studies and not all data were available from all studies, we were unable to include all studies in the meta-regression analysis and metaanalysis (only 12 out of 25 included studies). This resulted in a relatively small number of studies in some subgroups. For example, in the meta-regression analysis where we tested whether retirement type influenced the association between retirement and mortality, we analysed four studies for on-time retirement, seven for early retirement and two for retiring earlier. In the meta-analysis, we presented the results for on-time retirement from four studies. If more studies in the meta-regression and meta-analysis would have been available, then we could have provided more certainty to our effect sizes. Third, one study (Arrich et $a l^{57}$ ) was based only on patients with stroke. However, this study contributed little weight to the pooled HR in the insufficiently adjusted subgroup of studies for ontime retirement and mortality. Fourth, we did not include studies that investigated the influence of a retirement reform or offer (eg, by exploiting a natural experiment) in the metaregression analysis and meta-analysis since these studies used risk estimates that could not be pooled with the risk estimates of the included studies.

The findings of the current study have a number of implications and give direction to future research and policy. Since prior health status is an important factor in the association between retirement and mortality, in the context of an increasing retirement age, policymakers should consider health inequalities in the working population. Furthermore, we showed that there is an urgent need to consider information on demographics and prior health status in research on the association between retirement and mortality. Not adjusting for prior health status may lead to a biased conclusion that working longer results in living longer.

\section{CONCLUSIONS}

We did not find an association between early retirement, compared with continued work participation, and mortality. On-time retirement, compared with working beyond retirement, was associated with a higher risk of mortality. However, in the subgroup of studies that adjusted for prior health, we did not find an association between on-time retirement and mortality. Hence, when studying the association between retirement and mortality, it appears to be relevant to consider demographics as well as prior health status.

\section{What is already known on this subject}

- In recent years, there has been a growing interest in studying the impact of work and retirement on health.

- Several studies have assessed the impact of retirement age on mortality, but they have had mixed findings.

- A summary of available evidence on this topic and an analysis of whether and to what extent prior health status influences the association between retirement and mortality would help to clarify the situation.

\section{What this study adds}

- Early retirement was not associated with a higher risk of mortality.

- On-time retirement was associated with a higher risk of mortality, which might reflect the healthy worker effect.

- It is important to consider information on prior health and demographics when studying the association between retirement and mortality to avoid biased findings.

- Since prior health status is an important factor in the association between retirement and mortality, in the context of an increasing retirement age, policymakers should consider health inequalities in the working population.

Contributors RS, AdW, SS, PC, IL, CB and AvdB contributed to the design of the paper. RS, AdW, IL and PC performed the literature search and data analysis. RS participated in drafting the article. AdW, SS, PC, IL, CB and AvdB revised the article critically for important intellectual content.

Funding The authors have not declared a specific grant for this research from any funding agency in the public, commercial or not-for-profit sectors.

Competing interests None declared.

Patient consent for publication Not required.

Provenance and peer review Not commissioned; externally peer reviewed.

Open access This is an open access article distributed in accordance with the Creative Commons Attribution Non Commercial (CC BY-NC 4.0) license, which permits others to distribute, remix, adapt, build upon this work non-commercially, and license their derivative works on different terms, provided the original work is properly cited, appropriate credit is given, any changes made indicated, and the use is noncommercial. See: http://creativecommons.org/licenses/by-nc/4.0/. 
ORCID iD

Ranu Sewdas http://orcid.org/0000-0002-8774-0823

\section{REFERENCES}

1 Harbers M. Old-age dependency ratio, trends and projections in selected countries, 1950-2050, 2008.

2 Vaupel JW. Biodemography of human ageing. Nature 2010;464:536-42.

3 Sigg R, De-Luigi V. The success of policies aimed at extending working life, developments and trends in supporting dynamic social security. Geneva, Switzerland: International Social Security Association, 2016.

4 Cooke M. Policy changes and the labour force participation of older workers: evidence from six countries. Can J Aging 2006:25:387-400.

5 Duval R. The retirement effects of old-age pension and early retirement schemes in OECD countries, 2003

6 OECD. Aging and Employment Policies - Statistics on average effective age of retirement, 2017. Available: http://www.oecd.org/els/emp/ageingandemploymentpolicies.htm

7 OECD. Pensions at a glance 2017: OECD and G20 indicators. Paris: OECD, 2017.

8 van der Heide I, van Rijn RM, Robroek SJW, et al. Is retirement good for your health? A systematic review of longitudinal studies. BMC Public Health 2013;13:1180.

9 Zantinge EM, van den Berg M, Smit HA, et al. Retirement and a healthy lifestyle: opportunity or pitfall? A narrative review of the literature. Eur J Public Health 2014:24:433-9.

10 Platts LG, Webb E, Zins M, et al. Mid-life occupational grade and quality of life following retirement: a 16-year follow-up of the French GAZEL study. Aging Ment Health 2015;19:634-46.

11 Schuring M, Robroek SJW, Lingsma HF, et al. Educational differences in trajectories of self-rated health before, during, and after entering or leaving paid employment in the European workforce. Scand J Work Environ Health 2015:41:441-50.

12 Wang M, Shultz KS. Employee retirement: a review and recommendations for future investigation. J Manage 2010;36:172-206.

13 Rijs KJ, Cozijnsen R, Deeg DJH. The effect of retirement and age at retirement on selfperceived health after three years of follow-up in Dutch 55-64-year-olds. Ageing Soc 2012;32:281-306.

14 Zhu R. Retirement and its consequences for women's health in Australia. Soc Sci Med 2016;163:117-25

15 Byles JE, Vo K, Forder PM, et al. Gender, mental health, physical health and retirement: a prospective study of 21,608 Australians aged 55-69 years. Maturitas 2016;87:40-8.

16 Calvo E, Sarkisian N, Tamborini CR. Causal effects of retirement timing on subjective physical and emotional health. J Gerontol B Psycho/ Sci Soc Sci 2013;68:73-84.

17 van der Noordt M, IJzelenberg H, Droomers M, et al. Health effects of employment: a systematic review of prospective studies. Occup Environ Med 2014;71:730-6.

18 Marmot M. Social determinants of health inequalities. The Lancet 2005;365:1099-104.

19 Klumb PL, Lampert T, Women LT. Women, work, and well-being 1950-2000: a review and methodological critique. Soc Sci Med 2004;58:1007-24.

20 Rueda S, Chambers L, Wilson M, et al. Association of returning to work with better health in working-aged adults: a systematic review. Am J Public Health 2012;102:541-56

21 Schuring M, Robroek SJW, Burdorf A. The benefits of paid employment among persons with common mental health problems: evidence for the selection and causation mechanism. Scand I Work Environ Health 2017:43:540-9.

22 Harvey SB, Modini M, Joyce S, et al. Can work make you mentally ill? A systematic meta-review of work-related risk factors for common mental health problems. Occup Environ Med 2017;74:301-10.

23 Oksanen $\mathrm{T}$, Vahtera J, Westerlund $\mathrm{H}$, et al. Is retirement beneficial for mental health?: antidepressant use before and after retirement. Epidemiology 2011;22:553-9.

24 Jokela M, Ferrie JE, Gimeno D, et al. From midlife to early old age: health trajectories associated with retirement. Epidemiology 2010;21:284-90.

25 Stenholm S, Westerlund $\mathrm{H}$, Salo $\mathrm{P}$, et al. Age-related trajectories of physical functioning in work and retirement: the role of sociodemographic factors, lifestyle and disease. $J$ Epidemiol Community Health 2014;68:503-9.

26 Baker D, Packard M, Rader AD, et al. Mortality and early retirement. Soc Secur Bull 1982;45:3-10.

27 Myers RJ. Factors in interpreting mortality after retirement. J Amer statist Ass 1954;267:499-509.

28 Haynes SG, McMichael AJ, Tyroler HA. Survival after early and normal retirement. J Gerontol 1978;33:269-78.

29 Quaade T, Engholm G, Johansen AMT, et al. Mortality in relation to early retirement in Denmark: a population-based study. Scand J Public Health 2002;30:216-22.

30 Shim MJ, Gimeno D, Pruitt SL. A systematic review of retirement as a risk factor for mortality. In: Hoque N, McGehee MA, Bradshaw BS, eds. Applied demography and public health. Dordrecht: Springer Netherlands, 2013: 277-309.

31 Brockmann $\mathrm{H}$, Müller $\mathrm{R}$, Helmert U. Time to retire-time to die? A prospective cohort study of the effects of early retirement on long-term survival. Soc Sci Med 2009:69:160-4

32 Kuhn AWJ, Zweimuller J. Fatal attraction? Access to early retirement and mortality. IZA discussion papers 5160. The Institute for the Study of Labor (IZA), 2010
33 Kühntopf S, Tivig T. Early retirement and mortality in Germany. Eur J Epidemiol 2012;27:85-9.

34 Akinwale B, Lynch K, Wiggins $\mathrm{R}$, et al. Work, permanent sickness and mortality risk: a prospective cohort study of England and Wales, 1971-2006. J Epidemiol Community Health 2011;65:786-92.

35 Carlsson S, Andersson T, Michaëlsson K, et al. Late retirement is not associated with increased mortality, results based on all Swedish retirements 1991-2007. Eur J Epidemiol 2012;27:483-6.

36 Brandl SG, Smith BW. An Empirical Examination of Retired Police Officers' Length of Retirement and Age at Death. Police Q 2013;16:113-23.

37 Hernaes E, Markussen S, Piggott J, et al. Does retirement age impact mortality?J Health Econ 2013;32:586-98.

38 Kalwij A, Alessie R, Knoef M. Pathways to retirement and mortality risk in the Netherlands. Eur J Population 2013;29:221-38.

39 Lalive R, Staubli S. How does raising women's full retirement age affect labor supply, income, and mortality. Evidence from Switzerland, 2014.

40 Gopi Shah G, Ramnath S, Shoven JB, et al. The financial feasibility of delaying social security: evidence from administrative Tax data. Cambridge: National Bureau of Economic Research, Inc, 2015: 21544.

41 Hallberg $D$, Johansson $P$, Josephson $M$. Is an early retirement offer good for your health? quasi-experimental evidence from the army. J Health Econ 2015;44:274-85.

42 Luy M, Wegner-Siegmundt C, Wiedemann A, et al. Life expectancy by education, income and occupation in Germany: estimations using the longitudinal survival method. Comparative Population Studies 2015:40:399-436.

43 Fitzpatrick MD, Moore TJ. The mortality effects of retirement: evidence from social security eligibility at age 62. Cambridge: National Bureau of Economic Research, Inc. 2016: 24127.

44 Wu C, Odden MC, Fisher GG, et al. Association of retirement age with mortality: a population-based longitudinal study among older adults in the USA. J Epidemiol Community Health 2016;70:917-23.

45 Bloemen $\mathrm{H}$, Hochquertel S, Zweerink J. The causal effect of retirement on mortality: evidence from targeted incentives to retire early. Health Econ 2017;26:e204-18.

46 Hagen J. The effects of increasing the normal retirement age on health care utilization and mortality. J Popul Econ 2018;31:193-234.

47 Kontis V, Bennett JE, Mathers CD, et al. Future life expectancy in 35 industrialised countries: projections with a Bayesian model ensemble. Lancet 2017;389:1323-35.

48 Sewdas R DWA, Stenholm S, Coenen P, et al. Working longer, living longer? A systematic review, meta-regression analysis and meta-analysis on the association between retirement and mortality. PROSPERO: International prospective register of systematic reviews 2018:CRD42018092257.

49 Moher D, Liberati A, Tetzlaff J, et al. Preferred reporting items for systematic reviews and meta-analyses: the PRISMA statement. PLoS Med 2009;6:e1000097.

50 Hayden JA, Côté $P$, Bombardier C. Evaluation of the quality of prognosis studies in systematic reviews. Ann Intern Med 2006:144:427-37.

51 Coe NB, Lindeboom M. Does retirement kill you? Evidence from early retirement windows. SSRN Electronic Journal 2008

52 Litwin H. Does early retirement lead to longer life?Ageing Soc 2007;27:739-54.

53 Morris JK, Cook DG, Shaper AG. Loss of employment and mortality. BMJ 1994:308:1135-9.

54 Tsai SP, Wendt JK, Donnelly RP, et al. Age at retirement and long term survival of an industrial population: prospective cohort study. BMJ 2005:331:995.

55 Waldron H. Links between early retirement and mortality: social security administration, office of policy, office of research, evaluation, and statistics, 2001.

56 Wolfe JR. Perceived longevity and early retirement. Rev Econ Stat 1983;65:544-51.

57 Arrich J, Lalouschek W, Müllner M. Influence of socioeconomic status on mortality after stroke: retrospective cohort study. Stroke 2005;36:310-4.

58 Yasuda N, Toyota M, Koda S, et al. A retrospective cohort study on retirement and mortality for male employees of a local government of Japan. J Epidemiol 1998;8:47-51.

59 Anderson $\mathrm{KH}$. The effect of mandatory retirement on mortality. J Econ Bus 1985:37:81-8.

60 Bamia C, Trichopoulou A, Trichopoulos D. Age at retirement and mortality in a general population sample: the Greek EPIC study. Am J Epidemiol 2008;168:561-9.

61 Tyhurst JS, Salk L, KENNEDY M. Mortality, morbidity and retirement. Am J Public Health Nations Health 1957:47:1434-44.

62 de Wind A, Geuskens GA, Reeuwijk KG, et al. Pathways through which health influences early retirement: a qualitative study. BMC Public Health 2013;13:292

63 Pond R, Stephens C, Alpass F. How health affects retirement decisions: three pathways taken by middle-older aged New Zealanders. Ageing Soc 2010;30:527-45.

64 van Solinge $H$, Henkens K. Living longer, working longer? The impact of subjective life expectancy on retirement intentions and behaviour. Eur J Public Health 2010;20:47-51.

65 van Solinge $H$, Henkens $K$. Involuntary retirement: the role of restrictive circumstances, timing, and social embeddedness. J Gerontol B Psycho/ Sci Soc Sci 2007;62: S295-303.

66 Schaap R, de Wind A, Coenen P, et al. The effects of exit from work on health across different socioeconomic groups: a systematic literature review. Soc Sci Med 2018:198:36-45 
67 van der Zwaan GL, Oude Hengel KM, Sewdas R, et al. The role of personal characteristics, work environment and context in working beyond retirement: a mixedmethods study. Int Arch Occup Environ Health 2019;92:535-49.

68 de Wind AdeW, Geuskens GA, Ybema JF, et al. Health, job characteristics, skills, and social and financial factors in relation to early retirement - results from a longitudinal study in the Netherlands. Scand I Work Environ Health 2014;40:186-94.

69 van Rijn RM, Robroek SJW, Brouwer S, et al. Influence of poor health on exit from paid employment: a systematic review. Occup Environ Med 2014;71:295-301.
70 Homaie Rad E, Rashidian A, Arab M, et al. Comparison the effects of poor health and low income on early retirement: a systematic review and meta-analysis. Ind Health 2017:55:306-13.

71 Dingemans $E_{1}$ Henkens $\mathrm{K}$, Solinge H. Working beyond retirement in Europe: an investigation of individual and societal determinants using share, 2016.

72 Chowdhury R, Shah D, Payal A. Healthy worker effect phenomenon: revisited with emphasis on statistical methods - a review. Indian J Occup Environ Med 2017:21:2-8. 